\title{
Determination of 18ß-Glycyrrhetinic Acid in Human Serum Using the Fully Automated ALCA-System
}

\author{
Peter Heilmann ${ }^{1}$, Jürgen Heide ${ }^{2}$ and Manfred Schöneshöfer ${ }^{2}$
}

${ }^{1}$ Abteilung für Innere Medizin I (Endokrinologie und Stoffwechsel), Ruprecht-Karls-Universität Heidelberg, Heidelberg, Germany

2 Abteilung für Labormedizin, Krankenhaus Berlin-Spandau, Berlin, Germany

Summary: We report a method for the determination of 18ß-glycyrrhetinic acid (glycyrrhetinic acid) in human serum using the ALCA-system. The technology of the ALCA-system is based on the principles of adsorptive and desorptive processes between liquid and solid phases. The assay is run fully automated and selective. Procedural losses throughout the analysis are negligible, thereby allowing for external calibration. The calibration curve is linear up to $10 \mathrm{mg} / 1$ and concentrations as low as $10 \mu \mathrm{g} / 1$ are detectable. CV is $2.5 \%$ for within- and $7.5 \%$ for between-assay precision at a level of $50 \mu \mathrm{g} / 1$ and $1.2 \%$ for within- and $8.5 \%$ for between-assay precision at a level of $500 \mu \mathrm{g} / \mathrm{l}$. Specific and expensive reagents are not necessary and time-consuming manual operations are not involved. This assay can be selected from a wide spectrum of methods at any time. Thus, the present method is well-suited for drug monitoring purposes in the routine laboratory. In a pharmacokinetic study we measured serum levels of glycyrrhetinic acid in ten healthy young volunteers after ingestion of $500 \mathrm{mg}$ glycyrrhetinic acid. Maximum levels of glycyrrhetinic acid were $6.3 \mathrm{mg} / 12$ to 4 hours after ingestion. Twenty-four (24) hours after ingestion seven probands still had glycyrrhetinic acid levels above the detection limit with a mean level of $0.33 \mathrm{mg} / \mathrm{l}$.

\section{Introduction}

Glycyrrhetinic acid (fig. 1), the aglycon of glycyrrhizin, is a natural compound of the roots of Glycyrrhiza glabra L. For thousands of years it has been used as a sweetening agent as well as for therapeutic purposes (1). In 1946 Revers et al. (2) reported on the treatment of peptic ulcers with succus liquiritiae. Later he observed that about $20 \%$ of the patients treated with this medication developed edema and hypertension (3). Subsequently, this licorice-induced form of hypertension mediated by glycyrrhetinic acid has been described in several other reports $(4-7)$.
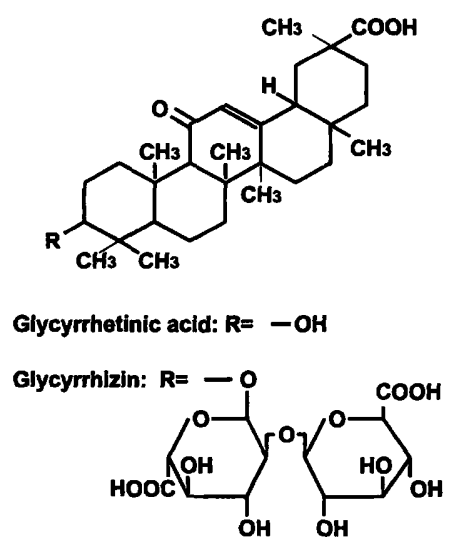

Fig. 1 Structure of glycyrrhizin and its aglycon glycyrrhetinic acid.
Methods for quantitative determination of glycyrrhetinic acid in human serum include thin layer chromatography (8), immunoassay techniques $(9,10)$, gas chromatography with mass spectrometry (11) and liquid chromatography (12-23). Most chromatographic procedures require time-consuming and tedious extraction steps for example enrichment, preconcentration and prepurification. Therefore liquid extraction or solid-phase extraction steps, sometimes combined with ion-pairing (12, $16,17,21)$, are used. An internal calibration is almost always necessary. Even the immunoassay procedures require prepurification steps when specific and sensitive results are intended.

We wanted to develop a non-immunological method for the determination of glycyrrhetinic acid that is implemented in a fully automated analytical system (automatic liquid chromatographic analyzer; ALCA) that allows for analyses to be run fully automated, selectively and within 17 minutes.

\section{Materials and Methods}

Materials

Glycyrrhetinic acid was obtained from Aldrich Chemie (Steinheim, Germany). All aqueous buffers were ready-to-use formulations (Chromsystems, München, Germany). The different $\mathrm{pH}$ buffers are mixed "on-line" by the pumps of the ALCA-system. 


\section{Apparatus}

The ALCA-system (Ancos) has been described in detail elsewhere (24-26) and is being used for the determination of other analytes. For the present method it has been slightly modified. The system consists of the sample clean-up unit, the chemical modulator unit and the analytical unit. The clean-up unit consists of pump 1 with a quarternary mixing device, an autosampler and precolumn 1 packed with reversed-phase material (PRP-I, $15 \mu \mathrm{m}$; Hamilton, Reno, NV, USA). The chemical modulator unit consists of the mixing chamber, precolumn 2 (packed with octadecyl-silica, $5 \mu \mathrm{m}$; Shandon Southern Products, Cheshire, UK) and pump 3. The analytical unit consists of pump 2, the analytical column (packed with octadecyl-silica, $5 \mu \mathrm{m}$; Shandon) and the UV-detector.

\section{Sample preparation}

Five hundred (500) microlitres of serum are mixed with $1 \mathrm{ml}$ of citric acid $(1 \mathrm{~mol} / \mathrm{l})$. No other sample preparation steps are necessary.

\section{On-line procedure}

The following analytical steps are time-controlled by the ALCAsystem in such a manner that steps $1-3$, as well as 7 and 8 , are run concomitantly with the chromatographic step 6 (for more details refer to 1 . c. $(24-26))$.

\section{Step 1}

The sample is transferred into the sampling loop of the autosampler. Concomitantly, precolumn 1 is equilibrated with a $\mathrm{pH} 8$ buffer.

\section{Step 2}

The sampling loop is switched into the analytical line and the sample is transferred onto precolumn 1. All lipophilic compounds are adsorbed, polar compounds are eluted.

\section{Step 3}

A mixture of $\mathrm{pH} 8$ buffer and methanol $(28+52$, by vol. $)$ is delivered by pump 1 at a flow-rate of $2.5 \mathrm{ml} / \mathrm{min}$. Substances more polar than glycyrrhetinic acid are eluted from precolumn 1 into the waste.

\section{Step 4}

A mixture of $\mathrm{pH} 8$ buffer and methanol $(18+82$, by vol.) is delivered at a flow-rate of $1.3 \mathrm{ml} / \mathrm{min}$; the glycyrrhetinic acid-containing fraction is eluted into the mixing chamber.

\section{Step 5}

Trifluoroacetic acid $(1 \mathrm{~mol} / \mathrm{l})$ is delivered by pump 3 into the mixing chamber at a flow-rate of $1.5 \mathrm{ml} / \mathrm{min}$. The glycyrrhetinic acid containing fraction is transferred to and focused onto the top of precolumn 2.

\section{Step 6}

Precolumn 2 is switched into line with the analytical column. A gradient of acetonitrile (raising from 60 to $90 \%$ within $8 \mathrm{~min}$ ) in $\mathrm{pH} 3$ buffer is delivered by pump 2 at a flow-rate of $1.3 \mathrm{ml} / \mathrm{min}$; the prepurified, focused fraction is chromatographed on the analytical column and separated glycyrrhetinic acid is quantified at $250 \mathrm{~nm}$ with the UV-detector. Then $100 \%$ acetonitrile is delivered by pump 2 for 1 min, followed by a mixture of acetonitrile and $\mathrm{pH} 3$ buffer $(60+40$, by vol.); the analytical column is cleaned and prepared for the next sample.

\section{Step 7}

In back-flush mode, an acetonitrile/trifluoroacetic acid gradient is delivered through precolumn 1 (flow-rate $=2.7 \mathrm{ml} / \mathrm{min}$ ); all resid- ual molecules more lipophilic than glycyrrhetinic acid are eluted into the waste.

Step 8

pH 8 buffer is delivered through precolumn 1; the matrix of precolumn 1 is equilibrated and prepared for adsorption of the next sample.

\section{Ingestion of glycyrrhetinic acid}

Ten healthy male students (aged 24 to 38 years) volunteered for the study. The course and the protocols of the study were explained to them carefully before they consented to participate. None of them had obvious evidence of metabolic, endocrine, renal, or hepatic disease. All denied taking any drugs or any preparation containing glycyrrhizin or glycyrrhetinic acid.

On the first day of the study $500 \mathrm{mg}$ glycyrrhetinic acid were given orally at $8 .^{00}$ a.m. Blood samples were taken $0,2,4,7$ and 10 hours after ingestion. Another blood sample was taken at $8 .^{00} \mathrm{a} . \mathrm{m}$. on the second day. Blood specimens were centrifuged immediately $(1750 \mathrm{~g})$ and serum was stored frozen until analysis.

\section{Results and Discussion}

\section{Procedural variables}

\section{Clean-up and chromatographical conditions}

Glycyrrhetinic acid is an acidic drug. Control of the eluent $\mathrm{pH}$, therefore, can convert this molecule from a neutral into an anionic species, and vice versa. Correspondingly, the plot of the retention time versus the $\mathrm{pH}$ shows an inflection point at about $\mathrm{pH} 7$ (fig. 2). For the preconcentration and cleaning-up of glycyrrhetinic acid, we used a pH 8 eluent. Then, glycyrrhetinic acid is eluted into the mixing chamber by increasing the methanol fraction. Admixing of trifluoroacetic acid into the mixing chamber at a flow-rate of $1.5 \mathrm{ml} / \mathrm{min}$ by pump 3 decreases the $\mathrm{pH}$ of the eluent as well as the concentration of methanol, so that the neutral form of glycyrrhetinic acid is focused onto the top of precolumn 2. By switching this column in line with the analytical column, glycyrrhetinic acid is transferred to the analytical column and efficiently separated from substances that have a physicochemical and chromatographical behaviour similar to glycyrrhetinic acid.

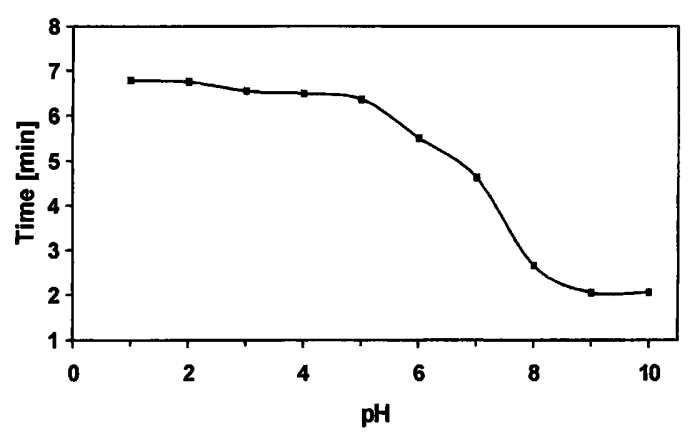

Fig. 2 Retention time of glycyrrhetinic acid on precolumn 1 in dependency on different $\mathrm{pH}$ levels of the eluent. 


\section{Efficacy of sample clean-up}

The efficacy of the sample clean-up procedure for elimination of non-specific, UV-absorbing chromogens was studied in serum samples spiked with $2.5 \mathrm{mg} / 1$ glycyrrhetinic acid. When the complete clean-up procedure is used, only a few non-interfering peaks are discernible in the final chromatogram (fig. 3A). The corresponding chromatogram from the same serum sample injected directly into the analytical system after manual solidphase extraction (fig. 3B) demonstrates the large interfering matrix background.

\section{Procedural losses}

To investigate the potential loss of glycyrrhetinic acid during the complete multistep analytical procedure, 100 $\mathrm{mg} / \mathrm{l}$ glycyrrhetinic acid dissolved in methanol and phosphoric acid, $0.02 \mathrm{~mol} / \mathrm{l}(50+50$, by vol.), was assayed. The eluate, which was not transferred to the analytical column, was monitored in the detector. No UV absorbance was detected, thus indicating that glycyrrhetinic acid was transferred almost quantitatively to the analytical column. During routine analyses, a check for potential analytical losses was run every tenth sample.

\section{Stability and quality of the chromatographic system}

For 600 serum samples that had been analyzed with the same instrument settings, the chromatographic resolution and peak shape were of consistent quality, as was the recovery of $2.5 \mathrm{mg} / 1$ glycyrrhetinic acid in a serum sample. There was no significant alteration of the retention time.

\section{Memory effect}

There was a memory effect of $5.65 \%$ when pure water was analyzed immediately following a sample containing $10 \mathrm{mg} / \mathrm{l}$ of glycyrrhetinic acid. Thus, low-level sam-

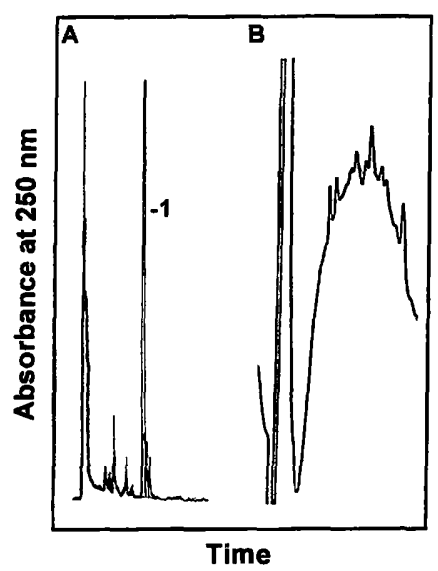

Fig. 3 Chromatograms of a serum sample spiked with glycyrrhetinic acid $(2.5 \mathrm{mg} / \mathrm{l})$ with $(\mathrm{A})$ and without $(\mathrm{B})$ using the full cleanup procedure of the ALCA system.

1 = glycyrrhetinic acid. ples run immediately after high-level samples have to be corrected correspondingly or have to be rerun. this memory effect is not due to residual amounts of glycyrrhetinic acid within the chromatographic system, but to the attaching of glycyrrhetinic acid to the teflon tubings in the sampling unit. Whereas the lipophilic glycyrrhetinic acid molecule is efficiently transported by organic mobile phases throughout the chromatographic system, it is significantly adsorbed onto to the lipophilic teflon surface, which is only flushed with polar solvents. Theoretically, this memory effect, therefore, could be eliminated by running a pure methanol sample after each serum sample. However, this procedure would render the method rather uneconomical and time-consuming.

\section{Analytical variables}

\section{Standard curve and sensitivity}

A standard curve for external calibration was set up in a serum sample, the concentrations ranging from $20 \mu \mathrm{g} / 1$ to $10 \mathrm{mg} / \mathrm{l}$. A linear calibration curve over the whole range was obtained when the peak area was evaluated $(y=505.5 x+16260.2 ; r=0.9998)$. The detection limit (a signal threefold the height of the noise level) was about $10 \mu \mathrm{g} / \mathrm{l}$. The sensitivity can be increased when $1 \mathrm{ml}$ serum is mixed with $0.5 \mathrm{ml}$ citric acid, but this may reduce the longevity of precolumn 1 . Unknowns were estimated by their peak area and the response factor from the calibration curve. This response factor was rechecked every twentieth sample by assaying a sample spiked with $500 \mu \mathrm{g} / \mathrm{l}$ of glycyrrhetinic acid.

\section{Imprecision}

Imprecision was assessed by replicate analyses $(n=8)$ of normal serum samples spiked with 50 or $500 \mu \mathrm{g} / \mathrm{l}$. Coefficients of variation were $2.5 \%$ for intra-assay precision and $7.5 \%$ for inter-assay precision at a level of $50 \mu \mathrm{g} / \mathrm{l}$ and $1.2 \%$ for intra-assay precision and $8.5 \%$ for inter-assay precision at a level of $500 \mu \mathrm{g} / \mathrm{l}$. The coefficient of variation for the precision of the retention time was $0.1 \%$ (intra-assay; $\mathrm{n}=30$ ).

\section{Accuracy}

Since accuracy control samples were not commercially available, analytical accuracy was determined by comparing the appropriate peak area of aqueous and serum samples spiked with $10 \mu \mathrm{g} / 1$ to $50 \mathrm{mg} / 1$ glycyrrhetinic acid. Accuracy was $98.5 \pm 1.8 \%(\mathrm{n}=12)$.

\section{Selectivity}

Serum samples of 10 healthy young volunteers before and after ingestion of $500 \mathrm{mg}$ of glycyrrhetinic acid were assayed. In four of the samples before ingestion of glycyrrhetinic acid there was no UV-absorbing peak eluting with a retention time similar to glycyrrhetinic 
acid. The other samples showed a UV-absorbing peak eluting with a retention time near that of glycyrrhetinic acid. In four cases this peak would simulate a concentration of glycyrrhetinic acid between 10 and $20 \mu \mathrm{g} / \mathrm{l}$. The other two cases had a concentration of $50 \mu \mathrm{g} / \mathrm{l}$. These concentrations were about 130 times below the mean maximum levels and about 6 times below the mean levels 24 hours after administration of glycyrrhetinic acid. Thirty-three (33) additional samples from in-patients were analyzed. Six (6) samples showed a UV-absorbing peak with a retention time adjacent to that of glycyrrhetinic acid (18.2\%). These peaks, if not discriminated as specific peaks, would simulate a concentration of glycyrrhetinic acid of 50 to $100 \mu \mathrm{g} / \mathrm{l}$ in 3 and below $50 \mu \mathrm{g} / 1$ in the remaining cases.

\section{Pharmacokinetics of glycyrrhetinic acid}

The serum levels of glycyrrhetinic acid in 10 healthy young volunteers after ingestion of $500 \mathrm{mg}$ of glycyrrhetinic acid are shown in figure 4. Maximum levels were reached after 2 (in 4 probands) or 4 hours (in 5 probands). One proband showed similar levels at both times. The mean maximum concentration was $6.3 \pm 3.1$ $\mathrm{mg} / \mathrm{l}$ (mean $\pm \mathrm{SD}$ ). Twenty-four (24) hours after in-

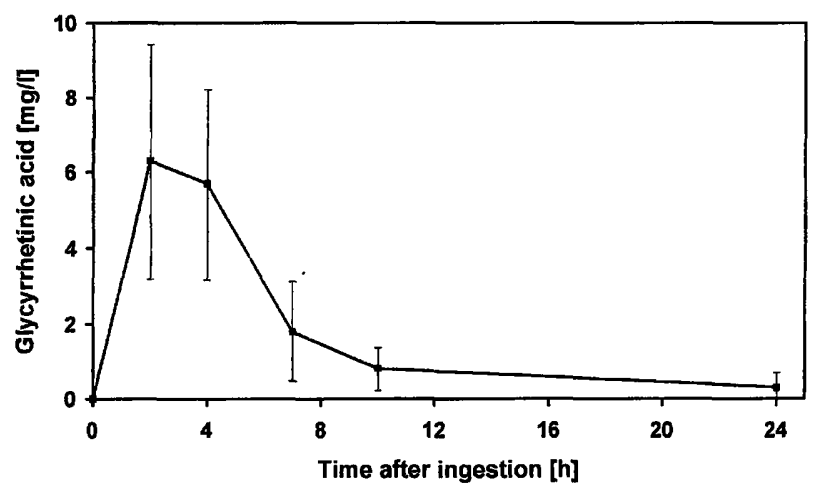

Fig. 4 Mean serum levels of glycyrrhetinic acid in ten healthy young volunteers before and $2,4,7,10$ and 24 hours after oral administration of $500 \mathrm{mg}$ of glycyrrhetinic acid (mean $\pm \mathrm{SD}$ ).

\section{References}

1. Davis EA, Morris DJ. Medicinal uses of licorice through the millennia: the good and plenty of it. Mol Cell Endocrinol 1991; 78:1-6.

2. Revers FE. Heeft succus liquiritiae een genezende werking op de maagzweer? Ned Tijdschr Geneesk 1946; 90:135-7.

3. Revers FE. Behandeling van ulcus ventriculi en ulcus duodeni met succus liquiritiae. Ned Tijdschr Geneesk 1948; 92:2968-73.

4. McKenzie MA, Hoefnagels WHL, Jansen RWMM, Benraad TJ, Kloppenborg PWC. The influence of glycyrrhetinic acid on plasma cortisol and cortisone in healthy young volunteers. J Clin Endocrinol Metab 1990; 70:1637-43.

5. Pratesi C, Scali M, Zampollo V, Zennaro MC, De Lazzari $P$, Lewicka S, et al. Effects of licorice on urinary metabolites of cortisol and cortisone. J Hypertens 1991; 9:274-5.

6. Stewart PM, Wallace AM, Valentino R, Burt D, Shackleton CHL, Edwards CRW. Mineralocorticoid activity of liquorice: gestion of glycyrrhetinic acid 7 probands still had measurable levels with a mean concentration of $329.9 \mu \mathrm{g} / \mathrm{l}$. These data are similar to those described by Krähenbühl et al. $(22,23)$. He administered three different doses of glycyrrhetinic acid $(500,1000$ and $1500 \mathrm{mg})$ and found maximum serum concentrations of $4.5 \pm 0.9 \mathrm{mg} / \mathrm{l}$ at 3.1 \pm 0.3 hours after ingestion. For the two higher doses he described a second elimination phase that was not seen at a dose of $500 \mathrm{mg}$. In another study De Groot et al. (12) administered 400 and $800 \mathrm{mg}$ glycyrrhizin daily over 4 weeks (corresponding to 229 and $458 \mathrm{mg}$ of glycyrrhetinic acid, respectively). In this study the levels of glycyrrhetinic acid were much lower compared with our data $(0.5-1.7 \mathrm{mg} / \mathrm{l})$. This may be explained with the need of conversion of glycyrrhizin to glycyrrhetinic acid in the intestinal tract as reported by Sakiya et al. (19). $\mathrm{He}$ found plasma concentrations of about $30 \mathrm{mg} / \mathrm{l}$ for glycyrrhetinic acid in rats after high oral doses $(500 \mathrm{mg} /$ $\mathrm{kg}$ glycyrrhizin), but no measurable plasma levels after a bolus injection of glycyrrhizin into the portal vein.

\section{Practicability}

The practicability of the present automated method for the determination of glycyrrhetinic acid provides distinct advantages over earlier ones:

(1) the complete assay is fully automated, thus eliminating any manual extraction or evaporation steps;

(2) the analyte is kept in solution throughout the complete assay, thereby avoiding potential losses or decomposition;

(3) procedural losses of glycyrrhetinic acid throughout the assay are negligible and because of the good precision only a single external calibration is necessary for evaluation of results; and

(4) the regeneration of the precolumns and the use of inexpensive solvents render the method distinctly more economical than immunoassay techniques.
$11 \beta$-hydroxy-steroid dehydrogenase deficiency comes of age. Lancet 1987; ii:821-4.

7. Farese RV, Biglieri EG, Shackleton CHL, Irony I, GomezFontes RN. Licorice-induced hypermineralocorticoidismus. N Engl J Med 1991; 325:1223-7.

8. Vampa G, Benvenuti S, Rossi T. Determination of glycyrrhizin and 180́-,18ß-glycyrrhetinic acid in rat plasma by high-performance thin-layer chromatography. Il Farmaco 1992; 47:82530 .

9. Kanaoka M, Yano S, Kato H, Nakada T, Kawamura K. Studies on the enzyme immunoassay of bio-active constituents contained in oriental medicinal drugs. IV. Enzyme immunoassay of glycyrrhetinic acid. Chem Pharm Bull 1988; 36:8-14.

10. Kanaoka M, Xano S, Kato H. Preparation of [3H]-3ß-hydroxy$18 \beta$ - and $\alpha$-glycyrrhetinic acid and radioimmunoassay of glycyrrhetinic acid. Chem Pharm Bull 1988; 36:3264-70. 
11. Itoh M, Asakawa N, Hashimoto Y, Ishibashi M, Miyazaki H. Quantitative analysis of glycyrrhizin and glycyrrhetinic acid in plasma after administration of FM-100 by using gas chromatography selected ion monitoring. Yakugaku Zasshi 1985; 105:1151-4.

12. De Groot G, Koops R, Hogendoom EA, Goewie CE, Savelkoul TJF, van Vloten P. Improvement of selectivity and sensitivity by column switching in the determination of glycyrrhizin and glycyrrhetinic acid in human plasma by high-performance liquid chromatography. J Chromatogr 1988; 456:71-81.

13. Zhang XY, Wu RJ, Chen JA, An DK. Determination of glycyrrhizin and its metabolite glycyrrhetinic acid in rabbit plasma by high-performance liquid chromatography after oral administration of licorzin. J Chromatogr 1989; 495:343-8.

14. Tsai TH, Chen CF. High-performance liquid chromatographic determination of $18 \beta$-glycyrrhetinic acid in rat plasma: application to pharmacokinetic study. J Chromatogr 1991; 567:405-14.

15. Tsai TH, Chen CF. Determination of glycyrrhizin in rabbit plasma by high-performance liquid chromatography with photodiodearray ultraviolet detection and its pharmacokinetic application. J Chromatogr 1992; 576 170-3.

16. Brown-Thomas JM, Christensen RG, Rieger R, Malone W, May WE. Determination of glycyrrhetinic acid in human plasma by high-performance liquid chromatography. J Chromatogr 1991; 568:232-8.

17. Yamamura Y, Kawakami J, Santa T, Kotaki H, Uchino K, Sawada Y, Iga T. Selective high-performance liquid chromatographic method for the determination of glycyrrhizin and glycyrrhetinic acid-3-O-glucuronide in biological fluids: application of ion-pair extraction and fluorescence labelling agent. $\mathbf{J}$ Chromatogr 1991; 567:151-60.

18. Yasuda K, Shibuya T, Nozaki M, Tsurumi H, Fujimura H, Kaneuchi F. Simultaneous determination of glycyrrhizin and glycyrrhetinic acid in plasma by high speed liquid chromatography. Zasshi Yakagaku 1978; 98:1545-7.

19. Sakiya Y, Akada Y, Kawano S, Miyauchi Y. Rapid estimation of glycyrrhizin and glycyrrhetinic acid in plasma by high- speed liquid chromatography. Chem Pharm Bull 1979; 27:1125-9.

20. Ichikawa T, Ishida S, Sakiya Y, Akada Y. High-performance liquid chromatographic determination of glycyrrhetinic acid in biological materials. Chem Pharm Bull 1984; 32:3734-8.

21. Hasler F, Krapf R, Bourquin D, Brenneisen R, Krähenbühl S. Determination of $18 \beta$-glycyrrhetinic acid in biological fluids from humans and rats by solid-phase extraction and high-performance liquid chromatography. J Chromatogr 1993; 20:73-82.

22. Krähenbühl S, Hasler F, Frey BM, Frey FJ, Brenneisen R, Krapf $R$. Kinetics and dynamics of orally administered $18 \beta$ glycyrrhetinic acid in humans. J Clin Endocrinol Metab 1984; 78:581-5.

23. Krähenbühl S, Hasler F, Krapf R. Analysis and pharmacokinetics of glycyrrhetinic acid in humans and experimental animals. Steroids 1994; 59:121-6.

24. Schöneshöfer M, Kage A, Weber B. New "on-line" sample pretreatment procedure for routine liquid-chromatographic assay of low-concentration compounds in body fluids illustrated by triamcinolone assay. Clin Chem 1983; 29:1367-71.

25. Schöneshöfer M, Kage A, Eisenschmid B, Heilmann P, Dhar TK, Weber B. Automated liquid chromatographic determination of the 20-dihydro isomers of cortisol and cortisone in human urine. J Chromatogr 1986; 380:267-74.

26. Tiel U, Heilmann P, Rejaibi R, Schöneshöfer M. Urinary oestriol-16-glucuronide determined by "on-line" liquid chromatography. J Clin Chem Clin Biochem 1989; 27:205-9.

Received January 23/April 29, 1997

Corresponding author: Dr. P. Heilmann, Department of Endocrinology and Metabolism, Luisenstraße 5, Gebäude 8, D-69115 Heidelberg, Germany

Fax: +49 (0)6221 564101, e-mail: p.heilmann@t-online.de 


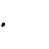

